June - 2008

\title{
Eportfolios: From description to analysis
}

\author{
Gabriella Minnes Brandes and Natasha Boskic \\ The University of British Columbia \\ Canada
}

\begin{abstract}
In recent years, different professional and academic settings have been increasingly utilizing ePortfolios to serve multiple purposes from recruitment to evaluation. This paper analyzes ePortfolios created by graduate students at a Canadian university. Demonstrated is how students' constructions can, and should, be more than a simple compilation of artifacts. Examined is an online learning environment whereby we shared knowledge, supported one another in knowledge construction, developed collective expertise, and engaged in progressive discourse. In our analysis of the portfolios, we focused on reflection and deepening understanding of learning. We discussed students' use of metaphors and hypertexts as means of making cognitive connections. We found that when students understood technological tools and how to use them to substantiate their thinking processes and to engage the readers/ viewers, their ePortfolios were richer and more complex in their illustrations of learning. With more experience and further analysis of exemplars of existing portfolios, students became more nuanced in their organization of their ePortfolios, reflecting the messages they conveyed. Metaphors and hypertexts became useful vehicles to move away from linearity and chronology to new organizational modes that better illustrated students' cognitive processes. In such a community of inquiry, developed within an online learning space, the instructor and peers had an important role in enhancing reflection through scaffolding. We conclude the paper with a call to explore the interactions between viewer/ reader and the materials presented in portfolios as part of learning occasions.
\end{abstract}

Keywords: Online learning community; hypertext; metaphor as learning tool; ePortfolio; cognition; scaffolding

\section{Introduction}

In recent years different professional and academic settings have been increasingly utilizing ePortfolios to serve multiple purposes from recruitment to evaluation. Definitions for ePortfolios range from a collection of artifacts, a method to capture development of ideas and learning, to a forum to interact within professional communities. An ePortfolio is often defined as "a digitized collection of artifacts, including demonstrations, resources and accomplishments that represent an individual, group, community, organization, or institution. This collection can be comprised of text-based, graphic or multimedia elements archived on a Web site or on other electronic media” (Lorenzo \& Ittelson, 2005, p. 3). Campbell, Cignetti, Melenyzer, Nettles and Wyman (2006) highlight the systematic and organizational aspects of ePortfolios. Helen Barrett (2007) suggests that ePortfolios ought to include, reflection, engagement and assessment for learning (see http://electronicportfolios.org/blog/index.html). Barrett emphasizes the key role reflection plays 
in the construction and substance of an ePortfolio, and therefore invites those who construct and teach how to use ePortfolios to include tools for scaffolding reflection: blogs, wikis, and digital stories. In a 2005 workshop at The University of British Columbia (UBC) entitled, Outside the Course Box: Digital Portfolios as New Spaces for Learning, Kathleen Blake Yancey, Clemson University, highlighted the importance of "linking" as a learning tool that is central to the construction of ePortfolios. Yancey argues that when students make explicit connections between various bodies of knowledge, they demonstrate learning. She wonders about the kinds of cognitive links that occur through the use of ePortfolios. She explores the possible unique connections between electronic linking within ePortfolios and cognitive linking.

This paper reports on the ways in which graduate students discussed, described, and analyzed their learning in the context of the construction of an ePortfolio for the culmination of studies in a Masters in Educational Technology (MET) program at the University of British Columbia. We ${ }^{1}$ were particularly interested in the ways in which students moved from a description of what they had learned, to an analytical discussion of how they had learned. We were intrigued by the supports necessary, and the steps taken, to encourage students to move from description to analysis.

This research was set to explore the ways in which ePortfolios become tools to enhance reflection. Specifically, we analyzed ePortfolios in terms of the use of hypertexts and metaphors as tools to demonstrate students' deepening understanding and learning.

We organized this paper around the key themes of our analysis. We conclude the paper with suggestions for teaching, as well as offering some comments about metaphors, hypertexuality, and scaffolding as important cognitive tools for online learning.

\section{Participants}

\section{Background}

The research reported here is based on the analysis of ePortfolios, which had been constructed as a part of an elective course, ETEC 590 (most often taken as the last course) in the MET program. The course had been taught four times and the data collected for this paper was based on the consent of 22 students ( $n=17$ males; $n=5$ females) who agreed to have their materials analyzed for this paper and their ePortfolios posted as examples for new students taking the course. The course has gone through major revisions based on students' feedback and the analysis that had been the basis for this paper. ETEC 590 is an online course which includes course content materials, group discussion forums posted on the course website, and a blog. Strategies for peer and instructor feedback are built into the course at various points. The major task for each student taking the course is to construct an ePortfolio.

\section{Data Collection and Methods of Analysis}

We were engaged in an ongoing, qualitative, self-study that focused on enhancing reflection through the use of ePortfolios in an online course. Students enrolled in the course were also invited to participate in the research (i.e., they provided consent for us to analyze their various contributions within the course). Data for this research were students' engagements in the small

\footnotetext{
${ }^{1}$ Gabriella Minnes Brandes is the instructor in the course discussed in the paper and Natasha Boskic is the instructional designer for the course. They have been collaborating since the initial steps of offering the course and throughout the years it has been taught.
} 
and large group discussions, their final ePortfolios, and the live oral presentations of their work. These were systematically analyzed to understand the multiple ways in which ePortfolios provided students with structures, tools, and opportunities for reflection.

Preliminary analysis occurred at the end of each round of teaching the course, which led to modifications within the course. Students' comments and initial analysis of the ePortfolios informed our understandings of ways to use ePortfolios to enhance student learning. After the second time the course was taught, and once we obtained Ethics approval and students' consent, we began a more systematic analysis of online discussions and the ePortfolios students created.

In our analysis of the ePortfolios, we move beyond examination of the organizational schemes of the portfolios to a deeper exploration of how they worked as vehicles for reflection. We established patterns and themes, highlighted anomalies and inconsistencies, and compared our findings with the theoretical framework we developed. Analyzed were the ways students used metaphors and hypertexts as opportunities to demonstrate learning. Systematically analyzed were the connections between online tools students used and their reflection on their own learning.

\section{Theoretical Framework: Reflection, metaphor and hypertext}

\section{Reflection}

Moon (2001) links reflection to learning as she discusses "surface" and "deep" approaches to learning. A "surface” approach involves memorization of details whereas a "deep" approach involves the integration of the new materials into existing knowledge, and the reconsideration of prior knowledge in light of new information. Moon suggests stages of representation of learning that highlight varying levels of depth of reflection. The stages move from noticing, to making sense, to making meaning and working with meaning and transformative learning. Clearly, the last three stages involve "deep" reflection. As a part of the learning activity, learners begin to develop a holistic view of what is learned - that is, more than the details included in the initial steps of memorization and accumulation of information. Learners link ideas to other ideas, construct relationships with prior knowledge, and provide evidence of restructuring ideas and evaluating the learning process. The construction of the ePortfolio provides students with a structure, which scaffolds a move into the stages of “deep” learning as students review their learning.

\section{Metaphors: “Metaphor ... is common to all our experiences and integral part of our daily life" MC}

Metaphors are an integral part of the language we use. They carry our perspective, point of view, assumptions, and conceptualizations of what it is that we are trying to understand or convey. Metaphors reflect different ways of approaching tasks (Collins \& Green, 1990). They highlight and coherently organize some aspects of our experience, and de-emphasize other aspects within the same experience (Marshall, 1988). Marshall analyzes different metaphors used to describe learning settings and compares working in recreational environments as metaphors to explore classroom learning. Marshall suggests that we carefully consider the metaphors we use so that we are aware of the benefits and limitations that they impose. Sfard (1998) argues that in order to reveal the most fundamental levels of thinking about how we learn, we need to expose and explore the metaphors we use when discussing learning. She identifies two metaphors: acquisition and participation. Sfard argues that metaphors allow us to "elicit some of the fundamental assumptions, underlying both our theorizing on learning and our practice” (p. 4). 
She asserts that metaphors are a tool for understanding; they are "a means for explaining the processes that turn old into new" (p. 4). Metaphors can enhance learning through the connections between the old and new, but can also limit the view of the new in light of the old. Martinez, Sauleda and Huber (2001) concur with Sfard's analysis of the role of metaphors in theorizing and discussing learning. They analyze metaphors pre-service teachers use as they describe learning. Most teachers in their study used transmission of knowledge as their key metaphor, whereas some used constructivist metaphors. Few teachers conceived of teaching and learning as a social process, however.

\section{Hypertextuality: "Education is not linear ... a whole network of systems to support the delivery” TI}

Constructivism and new theories of knowledge acquisition focus on student-centered practice where learning is characterized as an exploratory process building on student's prior knowledge, personal capabilities, interests, and preferences. Digital environments enable non-hierarchical, non-chronological, multi layered acquisition and utilization of knowledge (Chanen, 2007; Dobson \& Willinsky, 2007; Ensslin, 2004; Johnson-Eilola, \& Kimme Hea, 2003; Landow, 1997; Manovich, 2001). The networked way of thinking is supported by the hyper-linear electronic structure of the Web. Bolter (2001) points out that the "World Wide Web reflects 'multiple and developing' relationships between pieces of information” (p. 98). Banerjee (2004) argues that a reader of hypertext dismisses the boundaries of time and space to be in communication with different text. The human mind often works in non-linear associations, but there is also a need for coherence so that ideas are accessible and understandable (Schneider, 2005; Tyrkkö, 2007). Rose (2000) takes a more critical stand on the impact of hypertextuality. It is interesting to explore the relations between ideas established in hypertextual environment, and whether hyper linking breaks the natural flow of ideas, or it actually infuses a progression towards more complex structures. Numerous studies explore learner behaviour in digital spaces. Calisir and Gurel (2003) claim that a hypertextual structure increases "knowledgeable" participants' performance with respect to reading comprehension, while "non-knowledgeable" participants feel more comfortable in the linear text (Potelle \& Rouet, 2003; Rouet, 2003). Gardner (2003) wonders whether technology imposes impulsiveness, or it promotes critical thinking. Dillon and Gabbard (1998) question readers' response to hypermedia and their comprehension across media. How much control does a writer have in hypermedia environments over what the reader/viewer would glean from the materials posted? We analyzed our data with these questions in mind.

\section{Analysis}

\section{From Description to Analysis: Metaphors}

Participants were asked to find metaphors that will highlight their understanding of teaching, learning, and the use of technology. Primarily they used metaphors that were embedded in a constructivist theory of teaching and learning. 
Eportfolios: From description to analysis Brandes \& Boskic

Table 1. Participants, selected metaphors and context

\begin{tabular}{|c|c|c|c|}
\hline Student & Metaphor & Title & Context \\
\hline \multicolumn{4}{|c|}{ Winter 2006} \\
\hline SH & $\begin{array}{l}\text { Environment and } \\
\text { culture }\end{array}$ & $\begin{array}{l}\text { Technology and } \\
\text { tradition }\end{array}$ & North-West territories \\
\hline DK & $\begin{array}{l}\text { In a state of } \\
\text { continual } \\
\text { becoming }\end{array}$ & $\begin{array}{l}\text { Learning as a state of } \\
\text { continual becoming: } \\
\text { Past, present, forward }\end{array}$ & $\begin{array}{l}\text { Project Manager eLearning } \\
\text { Academy, Croatia }\end{array}$ \\
\hline $\mathrm{CM}$ & Open space & $\begin{array}{l}\text { Science, technology } \\
\text { and rural education }\end{array}$ & $\begin{array}{l}\text { High-school teacher. } \\
\text { Rural area, B.C. }\end{array}$ \\
\hline GP & $\begin{array}{l}\text { Ecological } \\
\text { metaphor }\end{array}$ & $\begin{array}{l}\text { Ecologies of } \\
\text { knowledge }\end{array}$ & Junior-high school teacher \\
\hline SR & Journey & $\begin{array}{l}\text { Trails through a } \\
\text { learning landscape }\end{array}$ & $\begin{array}{l}\text { College instructor, } \\
\text { Yukon }\end{array}$ \\
\hline MS & $\begin{array}{l}\text { Learning as } \\
\text { transformation }\end{array}$ & $\begin{array}{l}\text { Radical } \\
\text { transformations }\end{array}$ & $\begin{array}{l}\text { Transition from corporate to } \\
\text { education sector }\end{array}$ \\
\hline \multicolumn{4}{|l|}{ Fall 2006} \\
\hline GC & Highway & Route 06 & $\begin{array}{l}\text { K-5 teacher, Southern Vancouver } \\
\text { Island }\end{array}$ \\
\hline DC & $\begin{array}{l}\text { The island of } \\
\text { knowledge }\end{array}$ & Capstone Island & $\begin{array}{l}\text { General Tech class teacher, } \\
\text { Alberta }\end{array}$ \\
\hline $\mathrm{RF}$ & $\begin{array}{l}\text { Putting the cart } \\
\text { before the horse }\end{array}$ & $\begin{array}{l}\text { Keeping the horse } \\
\text { where it belongs }\end{array}$ & High-school physics teacher \\
\hline JG & Quest & $\begin{array}{l}\text { Yellow-brick road - A } \\
\text { journey in eLearning }\end{array}$ & Grades 5-7 teacher Northern BC \\
\hline GP & Bridges & $\begin{array}{l}\text { Bridging the } \\
\text { knowledge gap }\end{array}$ & BCIT, Vancouver \\
\hline NS & $\begin{array}{l}\text { Set of tools/Tool } \\
\text { shed }\end{array}$ & Shed filled with tools & $\begin{array}{l}\text { Behaviour intervention program, } \\
\text { English teacher, B.C. outside the } \\
\text { Lower Mainland }\end{array}$ \\
\hline PS & Exploration & $\begin{array}{l}\text { Mathematics in a sea } \\
\text { of technology }\end{array}$ & $\begin{array}{l}\text { High-school Math teacher, } \\
\text { Vancouver }\end{array}$ \\
\hline CT & $\begin{array}{l}\text { Learning as } \\
\text { transformation }\end{array}$ & $\begin{array}{l}\text { Learning as vision and } \\
\text { light }\end{array}$ & $\begin{array}{l}\text { Community college instructor, } \\
\text { business, technology, Vancouver }\end{array}$ \\
\hline \multicolumn{4}{|c|}{ Summer 2007} \\
\hline $\mathrm{BB}$ & Connection & $\begin{array}{l}\text { Connection: An } \\
\text { educational ePortfolio }\end{array}$ & $\begin{array}{l}\text { Grades 3-6 teacher, French } \\
\text { Immersion, B.C. }\end{array}$ \\
\hline DB & Workshop & Doug's workshop & $\begin{array}{l}\text { High-school Electronics, } \\
\text { Mechanics and Art Metal teacher } \\
\text { rural B.C. }\end{array}$ \\
\hline SB & Pendulum & $\begin{array}{l}\text { Education as a } \\
\text { transformative tool. } \\
\text { Balance in life and } \\
\text { teaching }\end{array}$ & Inner city school \\
\hline MC & Thread & $\begin{array}{l}\text { Thread: } \\
\text { Epistemology, } \\
\text { Technology \& Practice }\end{array}$ & Adult education, Alberta \\
\hline
\end{tabular}




\begin{tabular}{|c|c|c|c|}
\hline $\mathrm{TI}$ & Delivery tour & $\begin{array}{l}\text { edEx - Education } \\
\text { Express }\end{array}$ & $\begin{array}{l}\text { High-school teacher, Business } \\
\text { education, Vancouver }\end{array}$ \\
\hline $\mathrm{MM}$ & Climbing & $\begin{array}{l}\text { Reaching for higher } \\
\text { ground }\end{array}$ & $\begin{array}{l}\text { High-school history teacher, and U } \\
\text { of T, Ontario }\end{array}$ \\
\hline GT & $\begin{array}{l}\text { Through the } \\
\text { hoop and down } \\
\text { the rabbit hole - } \\
\text { transformation }\end{array}$ & $\begin{array}{l}\text { Through the hoop and } \\
\text { down the rabbit hole }\end{array}$ & $\begin{array}{l}\text { High-school teacher, Physics, } \\
\text { Math and Science, Vancouver }\end{array}$ \\
\hline MW & $\begin{array}{l}\text { Flower garden of } \\
\text { learning }\end{array}$ & Knowledge in bloom & $\begin{array}{l}\text { High-school } \\
\text { Computer/Information Technology } \\
\text { teacher First Nations students, } \\
\text { Vancouver Island }\end{array}$ \\
\hline
\end{tabular}

Eight of the 22 participants used variations on the journey metaphor where the traveler went through changes throughout the journey, and often the destination changed, as well as the traveler. Seven focused on the transformative elements of learning, and some related these transformations to gardening and growth. Five were inspired by their contexts and focused on learning within a community and making connections. Two used the overarching metaphor of the skills and tools needed for learning.

Students' metaphors are discussed in detail and then general conclusions are drawn on the use of metaphors to describe teaching as a way to illustrate deepening levels of understanding. In some cases students' metaphors encompassed more than one idea. For example, CT used the metaphor of learning as light, but she also examined the tools needed for learning. BB used the metaphor of community, but also highlighted connections within that community.

\section{Using Technology for Learning: A journey}

Many described their learning in the MET program as a journey. JG connected his metaphor to The Wizard of $\mathrm{Oz}$ as his learning took him on a journey on the Yellow Brick Road. GP likened his journey to crossing bridges; GC. described riding on highways and smaller roads; DC's journey took him to an island; and PS entitled his ePortfolio Mathematics in the sea of technology. TI was inspired by FedEx and entitled his portfolio EdEx, suggesting the fast pace of the journey and the move of information.

SR's title for her ePortfolio was: Trails through a learning landscape. When she described the structure of the portfolio and the various sections it included, SR wrote: "I chose the Inuit trail marker, the Inukshuk, to indicate the beginnings of new trails through my learning landscape. The trails are not isolated and may cross each other, but they are intended to act as 'advance organizers' to help others to understand the progress of my learning throughout the MET program in a coherent way." SR provided a visual map for the portfolio and explained that navigating through the site was a journey in itself.

\section{Using Technology for Learning: A transformation}

NS, MS, and CT used the metaphor of learning as a transformation. MM constructed his portfolio around mountain climbing, as he discussed his own growth and transformation when he climbed mountains and compared it to the completion of his graduate program. DK's and MS's metaphor was change, transformation, and growth. DK wrote about continual becoming, and MS explored ideas of "radical transformation". 
MS used a set of images to describe the process of transformation: a caterpillar to butterfly, seagull, airplane, and shuttle (Figure 1). Some transformations were not a natural maturation and growth process (evolutions), but rather a 'forced' metamorphosis - bird to airplane and shuttle. MS used a word "mutating" to express the "radical transformation". We knew from his biographical pieces, that MS decided to make a change in his career and move from business and technology areas into social sciences and learning. His belief in behaviourist approach started shaking under the influences of constructivist theories he encountered in the MET program, particularly as he examined the social implications of technology. Although it may look that MS's metaphors were too strong to relate to his learning experience, one may wonder about his interpretation of being radical.

Figure 1. Visual representation of transformation (Monte’s ePortfolio)

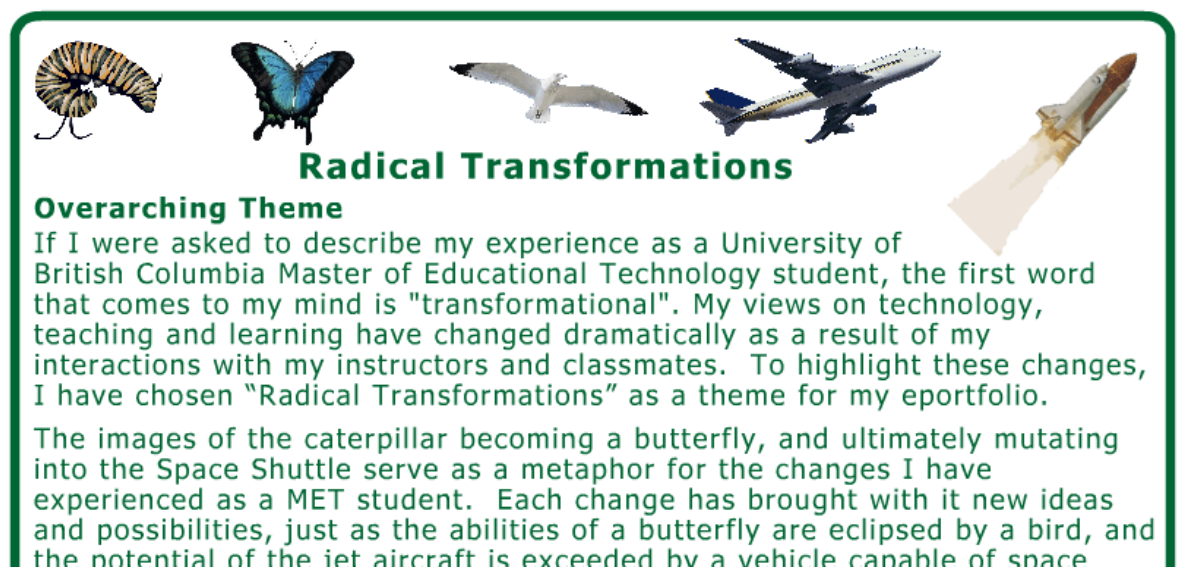

DK had undergone a similar transformation moving from an administrative and managerial job towards teaching. She saw her learning experience as a time-line of continual growth. DK did not use images to represent this process, but she successfully implemented a colour spectrum, allowing colours to sink into each other (rotate) with every change of different sections in her ePortfolio, and in that way she visually represented her own transformation.

In the most current offering of the course, GT used the metaphor Through the hoop and down the rabbit hole. He explained his reference to Lewis Carroll's Alice in Wonderland. "In wonderland, you need to be willing to re-examine some of your most fundamental assumptions, and I thought the same thing applied to the MET program about how to communicate effectively as well as what constitutes good pedagogy".

\section{Choosing a Metaphor that Reflects One's Context}

As students grappled with choosing their overarching question or metaphor to capture their learning and describe the influence of technology on teaching and learning, they often drew upon their own contexts and experiences. SH, SR, and CM were looking into their environments as they chose the metaphors and visuals for their portfolios. Although SR did not explicitly discuss context, she entitled the portfolio: Trails through a learning landscape, and she chose a visual representation and a metaphor that reminded her of her physical northern landscape. SR's context and landscape shaped her perceptions, worldview, and the representation she used. 
CM chose a notion of "open spaces" to talk about her learning. Her focus was on rural education and her metaphor was seen in the images of rural areas that she picked to 'decorate' specific sections of ePortfolio. SH went one step further, to explain how culture was embedded into environment. She explored the traditions of Tlicho Dene people, and applied the same principles of their creation story to her own "internal context". SH's ePortfolio was one example of the links between the external landscape and the metaphors used. She used the creation story of Tlicho Dene people to describe the construction of the ePortfolio, entitled Powerful allies for building educational resilience in Tlicho youth, which discussed multi-literacies and technology in a particular context. SH used traditional stories that carried traditional wisdom to highlight and introduce each section of the portfolio.

In the Dene Creation story, the original people began by deciding the essentials they needed and tied these essentials together in bundles. I chose to do the same. As my plan is to continue to develop and evolve this ePortfolio, I began by choosing the essentials and then I bundled these essentials together into common themes.

By reflecting on their personal experience of the MET program through the lenses of a metaphor, students were 'forced' to look back on their learning and life not only as a collection of various artifacts, but as evidence of their constant growth, a mirror of their beliefs, cultural values and, oftentimes, teaching perspectives. A selection of a metaphor was therefore not an easy task. On the contrary, for some, coming to a clear, meaningful, and focused representative word or image was mind-boggling, and sometimes painful. The final choice demonstrated and determined their personal contexts, both internal and external.

When we compared the metaphors students used to those Martinez and colleagues (2001) analyzed, our students did not have a surface level, transmission-oriented view of learning. They shared a constructivist paradigm, which led to view of learning as a transaction or a transformation. This difference could be explained in two ways. First, Martinez and colleagues analyzed pre-service teachers, while our participants were all experienced teachers working on their Masters degree. Secondly, the MET program is steeped in a constructivist paradigm, which is interwoven into many of the courses and therefore influences the ways in which our students viewed teaching and learning.

\section{Using Technology for Learning: Creating a community}

Different students emphasized that learning was done within a community and a context. Relying on their experiences in the MET program, they described how working with peers by exploring ideas in small and large groups, had shaped their understanding. One student highlighted the function of open source tools to encourage sharing ideas and teaching materials within a community. BB discussed relationships between people as a key element in teaching and learning. His portfolio traced a move from the personal to the professional, sociological, and cognitive aspects of learning as BB highlighted interpersonal connections and learning within a community. The starting point for the exploration in his ePortfolio was a particular belief about the importance of meaningful social interactions between young people and adults. This worldview (inspired by a book written by Gordon Neufeld) led BB to an analysis of technology and the use of technology in schools in light of questions of making interpersonal connections.

Having been influenced by Vygotsky's work on learning, MC chose the metaphor of intertwining threads and interconnectedness. MC invited us to look both at the individual and the social 
construction of knowledge. He argued that the ways in which teachers used technology was a reflection of what they thought about learning. The metaphor of the intertwining threads was an image that was used as the background and backdrop for learning. The text and visual representations of weaving and sewing helped pull his portfolio together.

\section{Using Technology for Learning: A set of tools}

When NS discussed the teachers' role when using technology, he used the metaphor of having a set of tools choosing appropriate tools for different tasks. He said: "There is always a best tool to get a job done, and so, as teachers, we must have access to a variety of tools. Good teachers recognize when a tool is good enough to get a job done well, and do not always rely upon the flashiest, most impressive tool available.” DB, a high school electronics, mechanics and art metal teacher, chose the metaphor of his "own workshop and its tools." As he discussed the use of technology in teaching, NS's view was complex. He encouraged teachers to use new technologies, new "tools", but cautioned from using tools just for their innovative qualities. He added:

Teachers should not be afraid of technology. Just because a tool is simple, does not mean that it is best. We cannot prepare students for the world of tomorrow by exclusively using yesterday's tools. Only by knowing the tools of our trade, which includes using them in a variety of ways, do we learn what works.

\section{From Description to Analysis: Using hypertexts}

Preparing to become competent and efficient users of technology, students applied their newly acquired knowledge throughout the program. The ePortfolio, being the culminating project, became the structure to represent what they had learned. Students chose a variety of tools to present their artifacts. $^{2}$ They used their personal experiences and worldviews as they constructed interactive and compelling webpages in their portfolios. They wanted their content to be informative and engaging, and at the same time, showcase their individualities and their cognitive and emotional involvement in the process of their learning. The process of developing a digital narrative by its nature includes hypertextuality (Bolter, \& Grusin, 1999). The relationships created by linking one piece of text to another added new layers to students' work. Students had to make critical decisions about what tools to use to present their ePortfolio; to anticipate the impact of their choices on the substantive nature of the portfolio and the audience's reception of their products. These decisions were analyzed to highlight the thinking processes that evolved throughout the course, and the links between the construction of ePortfolio and students' deepening understanding of their own learning.

Investigated was how students made connections between various parts of ePortfolios, and how they employed hyperlinks and how those hyperlinks supported the content of each portfolio. Did students use hyperlinks in order to offer additional information, enhance understanding with a personal insight, or simply because the technology enabled making connections to other external sources (i.e., text, visual or audio)? We were seeking evidence "how thought itself was reshaped

\footnotetext{
${ }^{2}$ In the first offering of the course, we presented three choices to students: iWebfolio, Took Kit and WebCT. Student Presentation Tool, some providing predetermined templates whereas others left more space for individual decisions. Since all students chose not to use templates we stopped presenting these options and students had free reign and choice in the tools they used.
} 
through interaction with the new modalities of wiring and language” (Calleja, \& Schwager, 2004, p.3) in students' ePortfolios and in their discussion in the forums.

Some students decided to develop simple webpages, while others chose more complex links (i.e., blogs, wikis, Flash templates). For the majority, the choices made required a lot of learning about technology and its effects. One of the required components of the ePortfolio course was a "tour guide" and a site-map where students explored and explicitly explained to the audience their considerations in the construction of the ePortfolio, its organization, components, and interrelations.

One of the basic functions of hyperlinks is to enable readers to move from one page to another. Some participants in our research did not go beyond that, offering one or maximum two layers of depth. Everything that was part of a website was visible from the homepage, or from its branches, as in GP's and CT's ePortfolios. Exceptions were sections called "links" or "resources" wherein the reference lists contained external links to journal articles or websites. There was no hyperlinking inside the content of the portfolio. In this manner, the individual who constructed the portfolio could control the readers'/viewers' navigation patterns easily and keep them focused. It was difficult to say, though, whether that was the writer's intention, or there were other reasons for not having nodes inside the content - i.e., staying closer to print-based writing practices.

Other students, however, used hypertexts in more complex ways. DK, for example, had links going to four different destinations: 1) to one of the ePortfolio pages (navigation, as with GP and CT); 2) to a wiki, which was a working and drafting space; 3) to a blog, which served as her journal that recorded her learning experiences through the MET program; and finally 4) to external resources for further exploration.

$\mathrm{SH}$, on the other hand, used links primarily to connect one piece of her writing to another, explaining terms, sharing her experience, and discussing her research. She had a limited number of occasions where her links took the reader outside of her ePortfolio, connecting to external resources (websites or articles). Since all the links connected to various aspects of the portfolio, there was less possibility to have 'dead links' after a certain period of time, as it had happened with CM's ePortfolio where a number of links to external sites were broken after a year.

Some students, as NS and CM, for example, used hyperlinks for a variety of purposes, linking to both internal and external sources, providing information or in-depth analysis. Hypertextuality and the use of metaphors served to support students' messages. They pushed students' thinking further, created opportunities to explore and create links, and enhanced “deep surface” learning.

\section{From Description to Analysis: Metaphors and hypertexts combined}

Hypertextuality is one tool that technology provides to illustrate deeper thinking through making explicit connections between ideas. Hypertexts provide technical, visual, and substantive ways to link ideas and make apparent connections between concepts. Similarly, metaphors are the second tool analyzed in this paper to demonstrate synthesis. Even when students used commonly held metaphors about learning, those metaphors had unique flavours. The medium of ePortfolios had hyperlinks that invited students to elaborate and illustrate the metaphors. In the most current group of students (Figure 2), since the instructor had been clearer on the connections between the use of links, hyperlinks and metaphors, students explored these ideas in depth. Their use of the language of metaphor provided a lens to explore learning and often shaped their decisions in 
construction of the portfolio and the use of hypertexts. Michael said: "Metaphor is a cognitive tool to draw connections, to connect concepts in an abstract way". Slavko did not organize the artifacts in the chronological order of taking the courses in the program, but organized the portfolio in a way that highlighted his metaphor. The pendulum became the substantive and organizational tool that has led the hyperlinks in the portfolio.

Figure 2. A collage of ePortfolios from Summer 2007

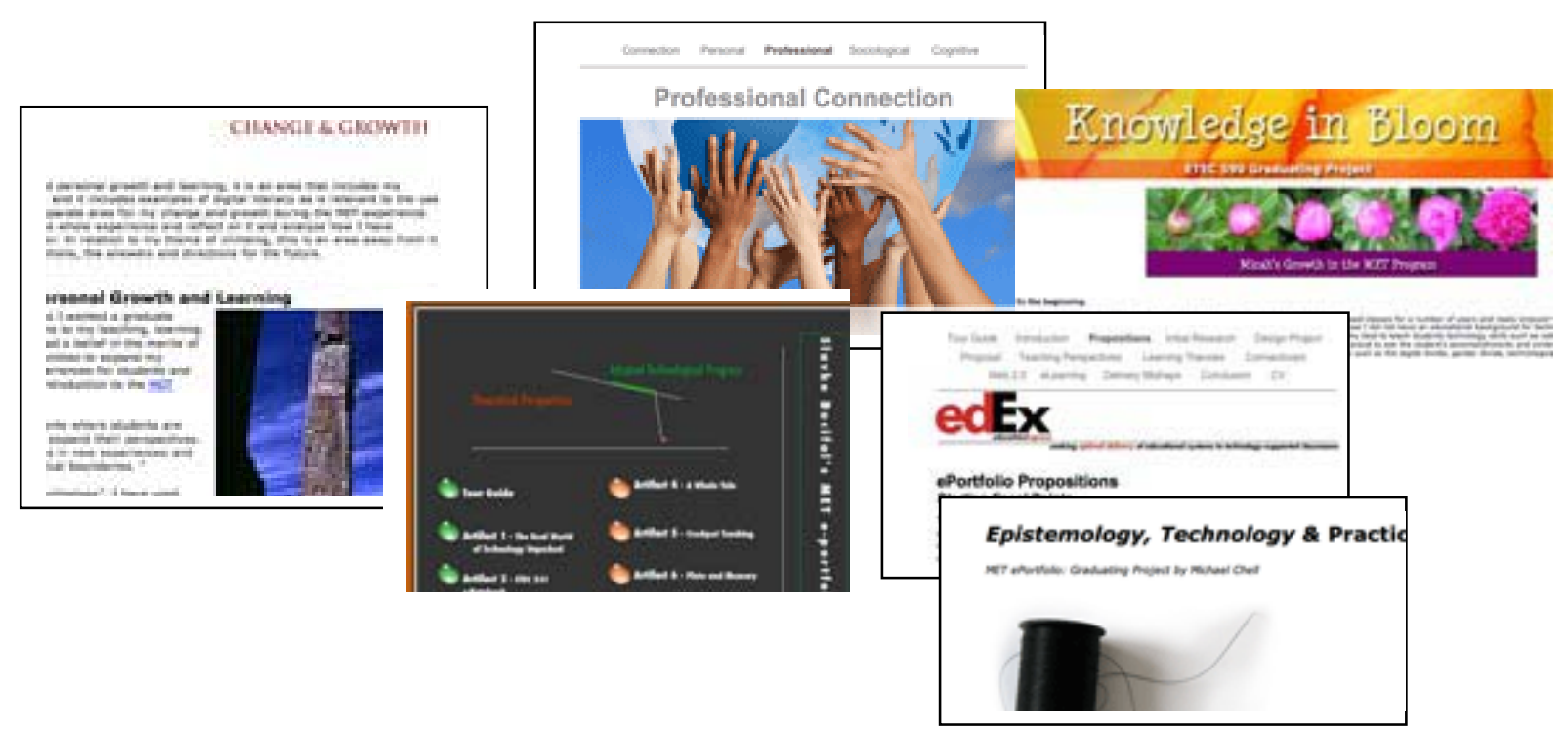

A different way in which the metaphors and hyperlinks were connected was demonstrated in DB's ePortfolio. He used visual tools (and the sidebar) to introduce each section. All those visuals and tools linked well to the overarching metaphor of learning as making choices of the appropriate tools within a workshop.

A sophisticated and elaborated juxtaposition of the metaphor and hypertextuality was in MC's portfolio. To emphasize learning as making connections, MC used the visual representation of threads. All visuals were needle/ thread related and appeared as sidebars, and at the top of the page for each section. MC moved beyond just using visual representations of threads as he used the language of sewing in his discussions of the artifacts:

In designing instructional materials, the complexity of the learner, the content and the learning situation must be considered. To tie in the thread metaphor, naturally dyed organic cotton thread has its value as does $100 \%$ Polyester. While it may not be the perfect solution, when it comes to learning theory I prefer the cotton/poly blend." “...Like in fashion, as the seasons change, the preference of different coloured thread will also change. It is not always easy to predict what the next trend will be.

The language of sewing created a cohesive portfolio. All discussions, reflections, and summaries in MC's portfolio were woven with the one organizing theme. It had become a lens through which MC analyzed teaching and learning. The reflection sections were woven into the reflective narratives, and were not always hyperlinked and had become an integral part of the portfolio. 


\section{ePortfolio organization}

Analysis of students' portfolios suggested that their approach to organizing their artifacts had evolved over time. Every new "generation" had, thanks to the generosity of previous ones, a growing pool of ePortfolio examples to learn from. In the first two course offerings, most students chose to organize their ePortfolio either by presenting artifacts in relation to individual courses, or by ordering them chronologically as they were developed throughout the program. By critiquing previous portfolios, and with instructor's guidance directed to other organizational choices, students chose to organize their portfolios around a metaphor, an overarching theme, or a question. These became the lens through which students explored their learning in the ePortfolio. The shift in organization was evident in students' navigation choices. While in the first offering, most ePortfolios were organized by the required elements (as taught in the course), the rationale, assessment rubric, teaching philosophy, courses, electives, reflections, the following offerings of the course already provided a change. Some students took liberties and reflected on their learning by organizing the artifacts around a metaphor, as suggested in the course content. The sections in GP's ePortfolio, which was organized around the metaphor of a bridge, were: Preparation, Foundations, Framework, and Spanning the Gap. The visuals in his portfolio also related to bridges. JG's Yellow brick road: A journey in eLearning, included the following titles to the various pages: Beginning, Off to be the Wizard, the Emerald City, Encounters with Oz, and Ruby Slippers. In the latest offering of the course, SB, BB, and MC, among others, organized their ePortfolios around themes, which shaped the content, language, and visuals. With an enhanced focus on possibilities for the organization of the portfolios, and a concerted effort to use metaphors and hypertexts as organizational mechanisms students' portfolios became more sophisticated and multi-layered.

\section{Teaching How to Move from Description to Analysis: Scaffolding}

Instructors have a key role to play when students are called upon to construct ePortfolios to enhance deep reflection and analyze what they learned. Matthews-DeNatale (2007), in a keynote address entitled ePortfolios in Action: An Evolving Learning Landscape, frames and describes the learning that occurs as students construct portfolios. She uses the metaphor of a construction of stories. Leaning on Mary Catherine Bateson's notions from her book Composing A Life (1989) Matthews-DeNatale argues that we learn through telling our stories as we piece together disconnected elements. This process calls for reflection and analysis that comes through the organization and reorganization of different artifacts. She asserts that stories can be seen as product, process, and cycle. We agree with Matthews-DeNatale that ePortfolios provide a tool and structure for students to document events, research, ideas, reflect, and analyze these ideas, use the analysis to inform the next steps, and then share their ideas with others.

In our experience, peer and instructor's feedback, as well as various scaffolding tasks that are built into the construction of the ePortfolio, all contribute to the move from description to analysis. In this section, examples of these scaffolding tasks are provided to illustrate how those helped students towards deeper engagement with the artifacts. Initially, students framed their portfolios and set-up structures that would allow integration of various components of the ePortfolio.

Framing could be done through a set of over-arching questions, values, or metaphors, which interweave the artifacts and create a meta-analysis structure that shapes the ePortfolio. (Course materials, week 4) 
Key questions in the course content and weekly tasks serve to scaffold student learning. One scaffolding task was the analysis of exemplars of portfolios, which provided students with language and examples of metaphors to think about their own portfolios, and tools that they could use to create them.

A third form of scaffolding occurred through online dialogue and instructor feedback. Each student submitted a proposal for the portfolio and received feedback from the instructor and a peer. Following is an example of the ways in which the instructor's feedback on the proposal provided a scaffold for a student, who was encouraged to move deeper in the analysis.

MW wrote his purpose for the portfolio in his proposal: "[To] create an organized document that shows off my learning ...connect my learning together for further reflection”. MW chose the metaphor of a flower garden. The instructor's feedback to the proposal was:

I was curious about the metaphor of the flowers in the garden. How does it shape your understanding of learning and teaching? What role does technology play in it? At the moment, it seems that you approach the portfolio as a compilation of artifacts. It is clear what you want included in the portfolio but not why you chose these artifacts and how they connect to one another and to a broader (more general and theoretical) question.

You make one comment about learning and deep reflection and that is about the role of time. How does this comment shape your understanding of teaching and learning? What differentiates "deep reflection” from any other reflection?

In response to the instructor's comments and questions, MW replied:

Thank you for your comments and feedback. Your comments are very helpful.

Presented below are some additional thoughts based on your feedback.

Knowledge in bloom - The garden metaphor is used to represent the complexities that are involved in the use of technology in educational environments. The flowers that will be included in my ePortfolio symbolize the many different issues that exist with technological use in an educational environment. The goal will be to link technological issues, which will be supported by artifacts with possible solutions that can act to provide guidance for other educators who may be struggling with the same issues. By providing possible solutions for complex issues surrounding technology, it is my hope that I can help others to provide a rich learning environment through which teachers can watch their student's knowledge bloom.

The dialogue between MW and the instructor continued with the instructor's reply:

I appreciated the continued dialogue and your clarification about the use of technology. You allude to some issues that arise from the use of technology in educational settings and you could clarify here what you mean. Once you clarify what kinds of issues or challenges you are referring to then the solutions would become more contextualized and relevant.

Consider further in what ways the metaphor of garden and knowledge blooming enhance how you define and determine learning. What are the pre-requisites? To 
use your metaphor - what is the water and how is it supplied? What fertilizer is used? Who decided how the garden in planted and tended for? What is the sun? soil?

Through that dialogue, MW shaped ideas about the construction of the portfolio:

The ideas that you mention such as the sun, soil and fertilizer are exactly what I have in mind. In addition, I plan to include a weed list to be symbolic of items that encroach upon educational technology such as acronym-based language.

As a result of that dialogue, MW was able to discuss specific examples and problems from his teaching practice in terms of the overarching metaphor he chose.

Peers also played an important part in scaffolding. In the last week of the course, each student presented the ePortfolio to the group, and during a question-answer period that followed, probed one another and asked for further clarification. As students replied to their peers' questions they considered new aspects of their organization, structure, and metaphor. These discussions often led to the final revisions of the ePortfolios.

\section{Conclusions}

Our goal, as instructor and designer, has been to support students in their engagement in knowledge building as they use technology to support learning (Scardamalia \& Bereiter, 2003). In our online learning environment, we developed and sustained a community of inquiry (Brandes \& Erickson, 1998, Erickson et al, 2005) whereby we shared knowledge, supported one another in knowledge construction, developed collective expertise, and engaged in progressive discourse. As students critiqued and analyzed the ePortfolios, they explored the ways in which these were constructed and how they matched their stated objectives and goals. Students developed criteria for evaluation of portfolios, which they could in turn use to assess their own work and that of their peers.

When students understand technological tools and how to use them, their ePortfolios are richer, more complex in the ways in which they illustrate learning. Metaphors and hypertexts become useful vehicles to move away from linearity and chronology towards new organizational modes that better illustrate students' cognitive processes. In such a community of inquiry that is developed within online learning spaces, the instructor and peers have an important role in enhancing reflection. They provide scaffolding necessary to move from description to analysis within a safe environment.

Martinez and colleagues (2001) call for professional development activities and, particularly, conversations that highlight construction and analysis of metaphors teachers use. This paper analyzed various opportunities for such dialogues. In our experience students asked one another primarily questions of clarification. Peers' questions and queries often led to new thoughts and further clarifications within the portfolios. The instructor carried the main responsibility for scaffolding through probes, challenges, and critiques that led students to think beyond what they had done. Perhaps because in online spaces these discussions are transparent and mostly done in the public spaces, students have more opportunities to learn how to probe and critique both their own and colleagues work. Instructor and students share a new language of the knowledge that is constructed through those discussions and enhances learning. 
As ePortfolios are used more, we must consider the ways in which their structures and organization reflect their messages. We must explore the different technologies available that will highlight the ideas explored in the portfolios. We must consider viewing the ePortfolios as learning opportunities for the students who construct them, as well as those who view them. We encourage research into the interaction between viewers/readers and the materials presented in the portfolio. We suggest providing different venues for reflection through analytical examinations of exemplars of ePortfolios, discussions of choices of tools, as well as opening spaces for explorations of new ideas and media. We encourage educators to use metaphors and hypertexts, as well as other ways, to enhance deeper reflection that shapes ePortfolios so that they are not just the compilation of artifacts, but occasions for learning.

\section{Acknowledgements}

We thank the anonymous reviewer and the editor for their comments on an earlier draft. We also acknowledge the graduate students in the Masters of Education program at the University of British Columbia who participated in the course and participated in this study.

\section{References}

Banerjee, P. (2004). Aesthetics of navigational performance in hypertext. AI \& Society, 18(4), 297-309.

Barrett, H. (n.d.). e-Portfolios for Learning blog. http://electronicportfolios.org/blog/index.html

Barrett, H. Supporting reflection in electronic portfolios: Blogs, wikis and digital storytelling. Vancouver, BC.: UBC ePortfolio.

Bateson, M. C. (1989) Composing a life. New York: Plume Printing.

Bolter, J. D. (2000). Writing Space: Computers, hypertext, and the remediation of print. Mahwah, NJ.: Lawrence Erlbaum Associates.

Bolter, J. D., \& Grusin, R. (1999). Remediation: Understanding new media. Cambridge, MA.: MIT Press.

Brandes, G. M., \& Erickson, G. L., (1998). Developing and sustaining a community of inquiry among teachers and teacher educators. The Alberta Journal of Educational Research, 44(1). 37-50.

Calisir, F., \& Gurel, Z. (2003). Influence of text structure and prior knowledge of the learner on reading comprehension, browsing and perceived control. Computers in Human Behavior, 19(2), 135-145.

Calleja, G., \& Schwager, C. (2004). Rhizomatic Cyborgs: Hypertextual considerations in a posthuman age. Technoetic Arts: A Journal of Speculative Research, 2(1), 3-15.

Campbell, B., Cignetti, D., Melenyzer, R., Nettles, P. \& Wyman, D. (2006). How to develop a professional portfolio ( $4^{\text {th }}$ edition). Boston: Pearson. 
Carter, L. (2003). Argument in Hypertext: Writing strategies and the problem of order in a nonsequential world. Computers \& Composition, 20(1), 3-22.

Chanen, B. W. (2007). Surfing the text. European Journal of English Studies, 11(2), 163-176.

Collins, E. C., \& Green, J. L., (1990) Metaphors: The construction of a perspective. Theory into Practice, 29(20), 71-77.

Dillon, A., \& Gabbard, R. (1998). Hypermedia as an Educational Technology: A review of the quantitative research literature on learner comprehension, control, and style. Review of Educational Research, 68(3), 322-349.

Dobson, T., \& Willinsky, J. (in press). Digital literacy. In D. Olson \& N. Torrence (Eds.), The Cambridge handbook of literacy.

Ensslin, A. (2004). Reconstructing the Deconstructed - hypertext and literary education. Language \& Literature, 13(4), 307-333.

Erickson, G. L., Brandes, G. M., Mitchell, J. A., \& Mitchell, I. J. (2005) Collaborative Teacher Learning: Findings from two professional development projects. Teaching and Teacher Education, 21(7) 787-798

Gardner, C. (2003). Meta-interpretation and Hypertext Fiction: A critical response. Computers \& the Humanities, 37(1), 33-56.

Johnson-Eilola, J., \& Kimme Hea, A. C. (2003). After Hypertext: Other ideas. Computers \& Composition, 20(4), 415-425.

Landow, G. P. (1997) Hypertext 2.0: The convergence of contemporary critical theory and technology. Baltimore, MD.: The Johns Hopkins University Press.

Lorenzo, G., \& Ittelson, J. (2005) An overview of ePortfolios, EDUCAUSE Learning Initiative. http://connect.educause.edu/Library/ELI/AnOverviewofEPortfolios/39335?time=121019 $\underline{8418}$

Manovich, L. (2001). The language of new media. Cambridge, MA.: MIT Press.

Marshall, H. H. (1988). Work or Learning: Implications of classroom metaphors. Educational Researcher, 17(9), 9-16. http://links.jstor.org/sici?sici=0013189X\%28198812\%2917\%3A9\%3C9\%3AWOLIOC\%3E2.0.CO\%3B2-L

Martinez, M. A., Sauleda, N., \& Huber, G. L. (2001). Metaphors as blueprints of thinking about teaching and learning. Teaching and Teacher Education, 17(8), 965-977

Matthews-DeNatale, G. (2007). Storytelling in the age of the Internet. EDUCAUSE Connect. http://connect.educause.edu/library/abstract/StorytellingintheAge/42327

Mitra, A., \& Cohen, E. (1999). Analyzing the Web: Directions and challenges. In S. Jones (Ed.), Doing Internet Research: Critical issues and methods for examining the Net (pp. 179203). Thousand Oaks, CA.: Sage. 
Moon, J. (2001). Reflection in higher education learning. Working Paper 4. York, UK.: The Higher Education Academy.

Ong, W. J. (1982). Orality and Literacy: The technologizing of the word. York: Routledge.

Potelle, H., \& Rouet, J. (2003). Effects of content representation and readers' prior knowledge on the comprehension of hypertext. International Journal of Human-Computer Studies, 58(3), 327-345.

Rose, E. (2000). Hypertexts: The language and culture of educational computing. London, ON.: Althouse.

Rouet, J. (2003). What was I looking for? The influence of task specificity and prior knowledge on students' search strategies in hypertext. Interacting with Computers, 15(3), 409-428.

Scardamalia, M., \& Bereiter, C. (2003). Beyond Brainstorming: Sustained creative work with ideas. Education Canada, 43(4), 4-8.

Schneider, R. (2005). Hypertext Narrative and the Reader: A view from cognitive theory. European Journal of English Studies, 9(2), 197-208.

Sfard, A. (1998). On two metaphors for learning and the dangers of choosing just one. Educational Researcher, 27(2), 4-13. http://links.jstor.org/sici?sici=0013189X\%28199803\%2927\%3A2\%3C4\%3AOTMFLA\%3E2.0.CO\%3B2-0

Tyrkkö, J. (2007). Making sense of digital textuality. European Journal of English Studies, 11(2), 147-161.

Yancey, K. B. (2006). An Exercise in Absence: Notes on the past and future of digital portfolios and student learning. SmartClassroom. http://campustechnology.com/articles/40690

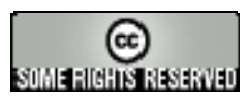

